\title{
The distribution and mitochondrial genotype of the hydroid Aglaophenia latecarinata is correlated with its pelagic Sargassum substrate type in the tropical and subtropical western Atlantic Ocean
}

\author{
Annette F. Govindarajan ${ }^{\text {Corresp., } 1}{ }^{\text {, Laura Cooney }}{ }^{2}$, Kerry Whittaker ${ }^{2}$, Dana Bloch ${ }^{2}$, Rachel Burdorf ${ }^{2}$, Shalagh \\ Canning $^{2}$, Caroline Carter ${ }^{2}$, Shannon M. Cellan ${ }^{2}$, Fredrik A. A. Eriksson ${ }^{2}$, Hannah Freyer ${ }^{2}$, Grayson Huston ${ }^{2}$, \\ Sabrina Hutchinson ${ }^{2}$, Kathleen McKeegan ${ }^{2}$, Megha Malpani ${ }^{2}$, Alexandra Merkle-Raymond ${ }^{2}$, Kendra Ouellette ${ }^{2}$, \\ Robin Petersen-Rockney ${ }^{2}$, Maggie Schultz ${ }^{2}$, Amy N. S. Siuda ${ }^{2,3}$ \\ ${ }^{1}$ Woods Hole Oceanographic Institution, Woods Hole, United States \\ 2 Sea Education Association, Woods Hole, Massachusetts, United States \\ 3 Marine Science Discipline, Eckerd College, St. Petersburg, Florida, United States \\ Corresponding Author: Annette F. Govindarajan \\ Email address: afrese@whoi.edu
}

The pelagic brown macroalga Sargassum supports rich biological communities in the tropical and subtropical Atlantic region, including a variety of epiphytic invertebrates that grow on the Sargassum itself. The thecate hydroid Aglaophenia latecarinata is commonly found growing on some, but not all, Sargassum forms. In this study, we examined the relationship between $A$. latecarinata and its pelagic Sargassum substrate across a broad geographic area over the course of four years (2015 - 2018). The distribution of the most common Sargassum forms that we observed (S. fluitans III and S. natans VIII) was consistent with the existence of distinct source regions for each. We found that $A$. latecarinata hydroids were abundant on both S. natans VIII and S. fluitans III, and also noted a rare observation of $A$. latecarinata on $S$. natans I. For the hydroids on S. natans VIII and S. fluitans III, hydroid mitochondrial genotype was strongly correlated with the Sargassum substrate form. We found significant population genetic structure in the hydroids, which was also consistent with the distributional patterns of the Sargassum forms. These results suggest that hydroid settlement on the Sargassum occurs in type specific Sargassum source regions. Hydroid species identification is challenging and cryptic speciation is common in the Aglaopheniidae. Therefore, to confirm our identification of $A$. latecarinata, we conducted a phylogenetic analysis that showed that while the genus Aglaophenia was not monophyletic, all $A$. latecarinata haplotypes associated with pelagic Sargassum belonged to the same clade and were likely the same species as previously published sequences from Florida, Central America, and one location in Brazil (São Sebastião). A nominal A. latecarinata sequence from a second Brazilian 
location (Alagoas) likely belongs to a different species. 
1 The distribution and mitochondrial genotype of the hydroid Aglaophenia latecarinata is

2 correlated with its pelagic Sargassum substrate type in the tropical and subtropical western

3 Atlantic Ocean

4

5 Annette Frese Govindarajan ${ }^{1}$, Laura Cooney², Kerry A. Whittaker ${ }^{2}$, Dana Bloch², Rachel

6 Burdorf $^{2}$, Shalagh Canning ${ }^{2}$, Caroline Carter $^{2}$, Shannon Maye Cellan ${ }^{2}$, Fredrik A. A. Eriksson ${ }^{2}$,

7 Hannah Freyer $^{2}$, Grayson Huston², Sabrina Hutchinson², Kathleen McKeegan², Megha Malpani²,

8 Alexandra Merkle-Raymond ${ }^{2}$, Kendra Ouellette ${ }^{2}$, Robin Petersen-Rockney ${ }^{2}$, Maggie Schultz $^{2}$,

9 Amy N.S. Siuda ${ }^{2,3}$

10

$11{ }^{1}$ Biology Department, Woods Hole Oceanographic Institution, Woods Hole, MA, USA

12 2Sea Education Association, Woods Hole, MA, USA

13 3 Marine Science Discipline, Eckerd College, St. Petersburg, FL, USA

14

15 Corresponding author:

16 Annette F. Govindarajan

17 afrese@whoi.edu 


\section{Abstract}

19 The pelagic brown macroalga Sargassum supports rich biological communities in the tropical

20 and subtropical Atlantic region, including a variety of epiphytic invertebrates that grow on the

21 Sargassum itself. The thecate hydroid Aglaophenia latecarinata is commonly found growing on

22 some, but not all, Sargassum forms. In this study, we examined the relationship between $A$.

23 latecarinata and its pelagic Sargassum substrate across a broad geographic area over the course

24 of four years (2015 - 2018). The distributions of S. fluitans III and S. natans VIII were consistent

25 with the existence of distinct source regions for each. We found that A. latecarinata hydroids

26 were abundant on both $S$. natans VIII and S. fluitans III, and also noted a rare observation of $A$.

27 latecarinata on S. natans I. For the hydroids on S. natans VIII and S. fluitans III, hydroid

28 mitochondrial genotype was strongly correlated with the Sargassum substrate form. We found

29 significant population genetic structure in the hydroids, which was also consistent with the

30 distributional patterns of the Sargassum forms. These results suggest that hydroid settlement on

31 the Sargassum occurs in type-specific Sargassum source regions, which are likely in the Gulf of

32 Mexico and equatorial Atlantic. Hydroid species identification is challenging and cryptic

33 speciation is common in the Aglaopheniidae. Therefore, to confirm our identification of $A$.

34 latecarinata, we conducted a phylogenetic analysis that showed that while the genus

35 Aglaophenia was not monophyletic, all $A$. latecarinata haplotypes associated with pelagic

36 Sargassum belonged to the same clade and were likely the same species as previously published

37 sequences from Florida, Central America, and one location in Brazil (São Sebastião). A nominal

38 A. latecarinata sequence from a second Brazilian location (Alagoas) likely belongs to a different 39 species. 


\section{Introduction}

43 Sargassum, a common brown macroalgae, is distributed globally from temperate to tropical ocean waters. Of the more than 350 recognized species (Guiry \& Guiry, 2018), S. natans and $S$.

fluitans are uniquely holopelagic (Butler et al., 1983; Stoner, 1983). These two species have several distinct forms that differ in their bladder and blade characteristics: $S$. natans is comprised of forms $I, I I$, VIII, and XI, and S. fluitans is comprised of forms $I I I$ and $I V$ (Parr, 1939; Schell et al., 2015). S. natans and S. fluitans lack holdfasts and reproductive structures (Parr, 1939), and new individuals derive from the fragmentation of existing individuals adrift at the sea surface. Pelagic Sargassum is ecologically important as an oasis of life on the oligotrophic open ocean. Individual clumps, 10 s of centimeters in each dimension, host abundant epiflora and epifauna that serve as the base of a complex food web similar to those found in benthic habitats (Butler et al., 1983; Coston-Clements et al., 1991). Mats of aggregated clumps measuring 10s of meters across additionally provide foraging or nursery habitat for fish (Wells \& Rooker, 2004), turtles

55 (Witherington et al., 2012), and seabirds (Moser \& Lee, 2012).

Mexico and less abundant or absent in the Caribbean Sea (reviewed in Butler et al., 1983). Since 2011, coastlines on both sides of the tropical Atlantic, including the Caribbean Sea, have experienced three discrete and unprecedented inundations of pelagic Sargassum, each lasting many months (Schell et al., 2015; Wang et al., 2019). The most recent event, during 2018, was the most extreme to date (Langin, 2018). Backtracking of landings using archived surface current model data (Franks et al. 2016), satellite observations (Wang \& Hu, 2017; Wang et al., 2019), and biophysical modeling (Brooks et al. 2018) indicate that these recent inundation events 
65 observations revealed that the inundating Sargassum was dominated by a previously rare form

66 (S. natans VIII) that is morphologically distinct from the two common forms (S. natans $I$ and $S$.

67 fluitans III) of pelagic Sargassum observed in the Sargasso Sea (Schell et al., 2015; Fig. 1).

68 Aglaophenia latecarinata (Allman, 1877) is a thecate hydroid that is commonly found on

69 pelagic Sargassum (Calder, 1993; Calder, 1997; Cunha \& Jacobucci, 2010; Fig. 2). In the

70 Sargasso Sea, A. latecarinata is a dominant hydrozoan on S. fluitans III while it is rare or absent

71 on S. natans I (Ryland, 1974; Niermann, 1986). Weis (1968) and Calder (1995) also report the

72 absence of $A$. latecarinata on $S$. natans, though they do not report the type of $S$. natans they

73 examined. A. latecarinata has been observed to be abundant, however, on S. natans VIII

74 (Burkenroad in Parr, 1939). A. latecarinata is found on a variety of substrates in other parts of its

75 range (Oliveira \& Marques, 2007; Moura et al., 2018). A. latecarinata forms feather-like

76 colonies of polyps that can reach up to $10 \mathrm{~mm}$ in height (Calder, 1997). Within a colony, polyp

77 fronds are connected via a stolon along the Sargassum substrate (Fig. 2). As the species lacks a

78 medusa stage, the hydroids release planula larvae which settle onto nearby substrates and

79 develop into new hydroids (Calder, 1997). For A. latecarinata on Sargassum substrates floating

80 over deep ocean regions, planulae likely originate from the same or nearby Sargassum.

81 Additionally, asexual fragments or propagules from the same or nearby Sargassum may also

82 generate new hydroid colonies (e.g., Pati \& Belmonte, 2018),

83 Species identification based on morphology in aglaopheniid hydroids is exceptionally

84 challenging (Svoboda \& Cornelius, 1991). Recent genetic analyses suggest abundant cryptic

85 speciation in the family and that A. latecarinata falls outside the main Aglaophenia clade

86 (Postaire et al., 2016; Moura et al., 2018). The geographic range of $A$. latecarinata includes the

87 northwestern Atlantic Ocean including the Sargasso Sea, the Gulf of Mexico, the southwestern 
88

Atlantic Ocean, and the western Pacific Ocean (Calder 1997); however, A. latecarinata from the Sargasso Sea has not been included in any of the molecular analyses to date.

Here, we examined the relationship between A. latecarinata and its most common pelagic Sargassum substrates. We sought to determine whether we could observe population genetic variation as detected by the $16 \mathrm{~S}$ gene over a vast geographic area in the tropical and subtropical western Atlantic Ocean, and if any observed variation could be associated with region and substrate type. A. latecarinata was collected from both S. natans VIII and S. fluitans III from the tropical and subtropical western Atlantic between 2015 and 2018. We report the first observations of abundant A. latecarinata on S. natans VIII since the 1930s (Burkenroad in Parr, 1939) as well as a single observation of $A$. latecarinata on $S$. natans $I$. We sequenced the $16 \mathrm{~S}$ gene from the hydroids on S. natans VIII and S. fluitans III and found that haplotypes were strongly associated with their Sargassum substrate type. We suggest that this finding could reflect hydroid colonization at different Sargassum source regions. We also show that in a family-level phylogenetic analysis of $16 \mathrm{~S}$ sequences, A. latecarinata falls outside the main Aglaophenia clade and that wide-ranging pelagic Sargassum-associated A. latecarinata is the same species as individuals collected in previous studies from Florida, Central America, and Sao Sebastiao, Brazil.

\section{Materials \& Methods}

\section{Sampling}

A. latecarinata samples were collected aboard the SSV Corwith Cramer between 2015 and 2018 during Sea Education Association cruises from the Canary Islands to the Caribbean (2015), from San Juan, Puerto Rico to New York, New York (2015) or Woods Hole, Massachusetts (2016) and from Nassau, Bahamas to New York, New York (2017 and 2018) via Bermuda, or from San 
111 Juan, Puerto Rico to Key West, Florida (2018) and the cruise tracks were mapped using Ocean

112 Data View 5.1.7 (Schlitzer, 2018) (Fig. 3). Cruise plans were filed with the US State

113 Department, who obtained the required collection permits. No permits were required for

114 sampling in international and US waters under federal jurisdiction. The cruise and permit

115 numbers for the samples collected in this study are as follows: C-259 US State Department

116 Cruise F2014-092, no permits necessary; C-263, US State Department Cruise F2015-044, no

117 permits necessary; C-266, US State Department Cruise F2015-083, no permits necessary; C-273,

118 US State Department Cruise F2016-084, Bermuda permit number SP170104, Bahamas

119 MAMR/FIS/13; C-277, US State Department Cruise F2017-067, Haiti permit number

120 SEMANAH/P-Nav/590, Dominican Republic permit (“Official Letter”) number 26940; and

121 C279, US State Department Cruise F2017-112, Bermuda permit number SP171103 and Bahamas

122 permit number MAMR/FIS/13.

123 During each cruise, instruments mounted in line with a clean seawater flow-through

124 system (intake at $\sim 3 \mathrm{~m}$ ) continuously measured temperature and salinity (Sea-Bird Electronics

125 SBE 45 MicroTSG), as well as relative chlorophyll- $a$ fluorescence (Turner Designs Model 10-

126 AU in vivo chlorophyll-a fluorometer). Sargassum specimens were primarily collected

127 opportunistically from dip nets that targeted distinct clumps. Less frequently, Sargassum clumps

128 were collected from a neuston net $(1 \mathrm{~m} \times 0.5 \mathrm{~m})$ with $335 \mu \mathrm{m}$ mesh towed alongside the ship at

129 two knots for 30 minutes. We aimed to collect a maximum of 10-12 clumps of each of

130 Sargassum form at every station. Each Sargassum clump was photographed and identified

131 morphologically using Parr (1939) and Schell et al. (2015) (Fig. 1). When present, multiple $A$.

132 latecarinata polyps from one individual hydroid (all connected by a visible stolon, Fig. 2) were

133 plucked from each Sargassum clump using sterilized forceps, preserved in 95\% ethanol as a 
134 single sample, and stored at room temperature. Vouchers of each Sargassum sample, including

135 the representative hydroid and epibiont community, were preserved in $95 \%$ ethanol. Four

136 representative vouchers that include A. latecarinata polyps attached to $S$. natans VIII and S.

137 fluitans III substrates were submitted to the Smithsonian Museum of Natural History (USNM

138 catalog numbers XXX-XXX).

139 Sequencing and population analyses

140 For molecular analysis, we sequenced hydroids found on S. fluitans III and S. natans VIII. The

141 hydroid colony on $S$. natans I was not included in our analysis given that it was a single

142 observation. Two to three polyps from each hydroid individual were removed from ethanol,

143 rinsed in deionized water, and diced using a sterilized razor blade. Genomic DNA (gDNA) of

144 each hydroid sample was extracted using a Qiagen DNeasy Blood \& Tissue Kit (Qiagen, USA)

145 following the manufacturer's protocol, and the final product was eluted twice using $100 \mu \mathrm{L}$ of

146 AE buffer. A segment of mitochondrial 16S rDNA was amplified using hydrozoan-specific

147 primers: HYD1: 5'-TCG ACT GTT TAC CAA AAA CAT AGC-3' and HYD2: 5'-ACG GAA

148 TGA ACT CAA ATC ATG TAA G-3' (Cunningham \& Buss, 1993). PCR amplification

149 consisted of an initial temperature of $95^{\circ} \mathrm{C}$ for $3 \mathrm{~min}$ followed by 35 cycles at $95^{\circ} \mathrm{C}$ for $30 \mathrm{~s}$,

$15045^{\circ} \mathrm{C}$ for $30 \mathrm{~s}$ and $68^{\circ} \mathrm{C}$ for $60 \mathrm{~s}$, and a final extension at $68^{\circ} \mathrm{C}$ for $5 \mathrm{~min}$. PCR products were

151 visualized on a 1.5\% agarose gel stained with SYBR ${ }^{\circledR}$ Safe (Invitrogen, USA). PCR products

152 were purified using QIAquick PCR Purification kits (Qiagen, USA) following the

153 manufacturer's protocol except that the final elution step was modified to yield $30 \mu \mathrm{L}$ total

154 volume. Purified amplicons were quantified using a Nanodrop ND-1000 spectrophotometer

155 (Thermo Fisher Scientific, USA) and sent to MWG Eurofins Operon (Huntsville, AL) or the

156 DNA Analysis Facility at Yale University (New Haven, CT) for bidirectional Sanger sequencing 
157 on an ABI 3730XL capillary sequencer. Sequences were submitted to GenBank (accession

158 numbers MK863834 - MK863972).

159 Geneious versions 9.0.5 and 11.0.5 were used to assemble and curate chromatographs

160 (Biomatters Ltd.). An alignment was generated with CLUSTALW (Larkin et al., 2007) using the

161 default settings in Geneious. The alignment was trimmed at both ends to remove low-quality

162 sequences. A haplotype network was constructed using TCS version 1.2.1 (Clement et al., 2000)

163 with gaps treated as a fifth character state.

164 Samples were categorized into broad oceanographic regions using QGIS (QGIS

165 Development Team (2018) (Fig. 4). Samples collected south of $30^{\circ} \mathrm{N}$ (the approximate location

166 of the subtropical convergence zone; Ullman et al., 2007) and north of the Greater Antilles were

167 categorized as from the South Sargasso Sea. Samples collected north of $30^{\circ} \mathrm{N}$ and south of the

168 Gulf Stream were categorized as from the North Sargasso Sea. Samples collected within the Gulf

169 Stream were categorized as such. Samples collected south of $20^{\circ} \mathrm{N}$ in or out of the Caribbean

170 were categorized as from the Caribbean or Tropical Atlantic, respectively. An Analysis of

171 Molecular Variance (AMOVA) was performed and pairwise $F_{\mathrm{ST}}$ 's calculated with Arlequin ver.

172 3.5.2 (Excoffier \& Lischer, 2010) to test for geographic structure between these regions.

173 Phylogenetic analysis

174 To confirm A. latecarinata species identification, we downloaded representative 16S sequences

175 for A. latecarinata and other aglaopheniid species from Genbank. Using ClustalW, we

176 constructed an alignment with the Genbank sequences and one representative of each of our

177 haplotypes from our short alignment. The ends of the alignment were trimmed and regions that

178 contained gaps that could not be aligned with confidence were removed. Maximum likelihood

179 and Bayesian analyses on this alignment were conducted using PAUP* (Swofford, 2003) and 
180 MrBayes (Huelsenbeck \& Ronquist, 2001) through the Geneious interface. The best-fit model

181 for these analyses was selected using Akaike Information Criterion using ModelTest (Posada \&

182 Crandall, 1998). In the maximum likelihood analysis, a phylogeny was constructed using the

183 selected model and support for the nodes was determined with a bootstrap analysis with 1000

184 replicates. The Bayesian analysis was run with a chain length of 1,100,000, a subsampling

185 frequency of 1,000, a burn-in of 100,000, 4 heated chains, and a heated chain temperature of 0.2 .

186 Results

187 Sampling

188 A total of 140 A. latecarinata colonies were collected at 47 stations across the Tropical

189 Atlantic, Caribbean, South Sargasso Sea, North Sargasso Sea, and Gulf Stream regions (Fig. 4;

190 SI Table 1) and sequenced. The distribution of $A$. latecarinata samples across two Sargassum

191 forms was nearly even, with 68 colonies collected from S. natans VIII and 71 colonies collected

192 from S. fluitans III. Only one A. latecarinata colony was observed on S. natans I (from the

193 North Sargasso Sea in 2015) despite frequent observations of S. natans I throughout multiple

194 cruises. The temporal and geographic distribution of Sargassum forms represented in the dataset

195 was quite variable due to episodic S. natans VIII inundations from the equatorial Atlantic and

196 predetermined cruise tracks (Table 1). However, because dip net sampling was selective, sample

197 density is not necessarily representative of actual Sargassum density. For a representative view

198 of Sargassum distribution and relative abundance, refer to Schell et al. (2015). In 2015, 20 of 21

199 A. latecarinata samples were collected from S. natans VIII at stations in the Tropical Atlantic. Of

200 the 40 samples collected in 2016, a majority were again collected from S. natans VIII, and some

201 from stations in the South Sargasso Sea $(n=20)$ and northern Gulf Stream $(n=12)$. In contrast,

202 most (43 out of 46) samples in 2017 were collected from S. fluitans III at stations in the southern 
203 Gulf Stream $(n=5)$, South Sargasso Sea $(n=36)$ and North Sargasso Sea $(n=2)$. In 2018,11

204 samples were collected from S. natans VIII and 14 samples were collected from S. fluitans III in

205 the South Sargasso Sea, while 6 samples were collected from S. fluitans III in the North Sargasso

206 Sea. The number of Sargassum clumps collected per station ranged from one to 12; only at four

207 of 47 stations (C266-005, C266-011, C277-020, C279-003) were we able to concurrently collect

208 A. latecarinata samples from S. natans VIII and S. fluitans III. These stations were all located in

209 the South Sargasso Sea.

210 Sequence variation

211 A 500 base pair alignment was obtained after trimming the sequence ends to remove low-quality

212 regions. The alignment had 8 variable positions, 4 of which were indels, that comprised 10

213 unique haplotypes. Haplotype frequency and diversity were strongly associated with algal

214 substrate, with only one haplotype (haplotype 1) growing on both S. natans VIII and S. fluitans

215 III (Fig. 5). Of the 68 A. latecarinata colonies found on S. natans VIII, 65 were haplotype 1, two

216 were haplotype 2, and one was haplotype 3 (Fig. 5). Of the 71 A. latecarinata colonies found on

217 S. fluitans III, two were haplotype 1, 44 were haplotype 4, one was haplotype 5, four were

218 haplotype 6, one was haplotype 7, 13 were haplotype 8 , one was haplotype 9 , and five were

219 haplotype 10 (Fig. 5). There were only two colonies collected from S. fluitans III that had an "S.

220 natans VIII' haplotype (haplotype 1; these were 2016_SF3_41 from the South Sargasso Sea and

221 2017_SF3_65 from the Gulf Stream, SI Table 1). No colonies on S. natans VIII possessed an " $S$.

222 fluitans III' haplotype. To confirm that our results were consistent over a longer sequence length,

223 we constructed an alternative alignment with a subset of sequences that had expanded high-

224 quality reads (590 base pairs for 99 sequences). The resulting haplotype analysis was consistent

225 with the one based on the shorter, but more inclusive, alignment (Suppl. Fig. 1). 
We found significant geographic structure between regions (Table 2). Pairwise $F_{\mathrm{ST}}$ values

227

228

229

230

231

232

233

234

235

236

237

238

239

240

241

24

243

244

245

246

247

ranged from 0.02030 between the South and North Sargasso Seas, to 0.62631 between the North

Sargasso Sea and the Tropical Atlantic (Table 3). All comparisons were significant $(\mathrm{p}<0.05)$

except for between the South and North Sargasso Seas.

Phylogenetic placement

We combined representative sequences of each of our A. latecarinata haplotypes with $16 \mathrm{~S}$ sequences from aglaopheniid species on Genbank (Table 4). In instances when multiple sequences for a given species were present, we selected one sequence to represent that species, with the exception of $A$. latecarinata, for which we used all available sequences. The GenBank A. latecarinata sequences originated from two locations in the southern hemisphere (São Sebastião and Alagoas, Brazil), and 5 locations in the northern hemisphere ranging from Panama to Fort Pierce, Florida. The Florida sequence, which interestingly was the only specimen noted to originate from a hydroid colony on Sargassum, although the species of Sargassum was not given; (Moura et al., 2018), matched one of our haplotypes. The rest of the Genbank $A$.

latecarinata sequences were unique. Our trimmed alignment was 378 base pairs. Our maximum likelihood and Bayesian phylogenetic analyses showed that the northern hemisphere sequences (including ours) formed a weakly supported clade (bootstrap and Bayesian posterior probability values were 66 and .69, respectively; Fig. 6). This clade, plus the São Sebastião sequence, formed a strongly supported clade (bootstrap and Bayesian posterior probability values were 98 and 1, respectively; Fig. 6). The A. latecarinata sequence from Alagoas, Brazil, fell outside of the main A. latecarinata clade and clustered strongly with Aglaophenia rhynchocarpa (ML bootstrap and Bayesian posterior probability values were 100 and 1, respectively; Fig. 6). The genus Aglaophenia was not monophyletic although support for the arrangement of the nodes was 
249 generally weak - often less than 50 in the ML bootstrap analysis, but occasionally higher in the

250 Bayesian analysis (Fig. 6).

\section{Discussion}

252 Our results add to growing evidence from field and satellite observations that Sargassum forms

253 have different source regions and dispersal patterns (Gower \& King 2011; Gower et al., 2013;

254 Schell et al., 2015; Wang and Hu, 2017). The distinct but overlapping geographic ranges of $S$.

255 fluitans III and S. natans VIII observed in Schell et al. (2015) are also evident in our pattern of

256 opportunistic sample collection. S. natans VIII was abundant in the Tropical Atlantic and also

257 present in the northern Gulf Stream during some years. S. natans VIII and S. fluitans III co-

258 occurred in the South Sargasso Sea.

259 Prior to 2011, the primary forms of Sargassum in the Sargasso Sea were S. fluitans III

260 and S. natans I (Schell et al., 2015). Satellite data from this time suggests these forms range from

261 the Caribbean to the Sargasso Sea and likely originate from the Gulf of Mexico (Gower \& King,

262 2011). In contrast, S. natans VIII is likely transported from its source in the North Equatorial

263 Recirculation Region via the North Equatorial Current, which splits into the Caribbean Current

264 in the Caribbean Sea and the Antilles Current that runs north of the Greater Antilles (Franks et

265 al., 2016; Putnam et al., 2018; Brooks et al., 2018; Wang et al., 2019). S. natans VIII from the

266 Caribbean may then be carried into the Gulf of Mexico and on to the Gulf Stream, where it could

267 mix and travel north along with the S. natans VIII from the Antilles Current (Wang et al., 2019).

268 Because the boundary between the Antilles Current and South Sargasso Sea is weak, both $S$.

269 fluitans III and S. natans VIII are commonly found in this region (Schell et al., 2015).

270 The seasonality of the blooms and their associated dispersal may also contribute to the

271 maintenance of distinct distributions of each Sargassum type and their associated A. latecarinata 
272 genotypes. Both the Gulf of Mexico and the tropical Atlantic exhibit Sargassum blooms in

273 spring (Wang et al., 2019). We suggest that the Gulf of Mexico Sargassum (which likely

274 includes $S$. fluitans III) may be exported to the North Atlantic before the tropical Atlantic

275 Sargassum (which is likely S. natans VIII) arrives there, thus minimizing the potential for

276 interaction of their associated hydroids. Additional sampling of both the hydroids and the

277 Sargassum in the Gulf of Mexico and equatorial Atlantic source regions will be necessary to test

278 our proposed mechanism for maintaining distinct A. latecarinata populations.

279 Our frequent observations of A. latecarinata on S. fluitans III and S. natans VIII and

280 single observation of A. latecarinata on S. natans I are consistent with previous findings.

281 Burkenroad (in Parr, 1939) reported that A. latecarinata (reported as A. minuta) was the

282 dominant hydroid on both S. fluitans III and S. natans VIII. Ryland (1974) and Niermann (1986)

283 also did not report A. latecarinata on their surveys of epibionts on S. natans I. Weis (1968) did

284 not find A. latecarinata on S. natans and Calder (1995) identified A. latecarinata as the dominant

285 hydrozoan on $S$. fluitans, but noted that it was entirely absent from S. natans. Neither Weis

286 (1968) nor Calder (1995) specified the type of S. natans that they observed, but we suggest that it

287 was likely the S. natans I form. Settlement specificity of hydroid species has been observed both

288 within and between other Sargassum species (Nishihira, 1965; Nishihira, 1971; Calder, 1995).

289 The species-specific substrate pattern that we observed could be due to several factors

290 including substrate selection by planula larvae or substrate availability. For example, larvae of

291 the epiphytic hydroid Coryne uchidae (Stechow) showed larval settlement preferences when

292 presented with multiple algal substrates including different non-pelagic Sargassum species

293 (Nisihira, 1968a). Substrate selection in C. uchidae appears to be influenced by chemical cues

294 present in substrate extracts (Nisihira, 1968b; Kato et al., 1975). We are not aware of any similar 
295 experiment with A. latecarinata larvae. However, A. latecarinata hydroids have been

296 successfully transplanted on to S. natans I (Burkenroad in Parr, 1939) suggesting that the

297 hydroids can grow on this Sargassum species if settlement occurs. If the different Sargassum

298 species have distinct source regions as recent research suggests (Schell et al., 2015; Franks et al.,

299 2016; Wang and $\mathrm{Hu}, 2017)$, and larval settlement occurs in these source regions where the

300 Sargassum species are not found together, it is possible that substrate availability is primarily

301 responsible for our, and previous, observations. Hydroid colonies could also potentially originate

302 asexually via dislodged fragments attaching to Sargassum, and this could lead to species-specific

303 patterns if re-attachment were substrate-specific. More research is needed to determine the

304 degree of substrate specificity as well as the mechanisms driving any specificity, both for pelagic

305 A. latecarinata and for aglaopheniids in general.

306 For the S. fluitans III and S. natans VIII, which had abundant A. latecarinata

307 colonization, we found a striking correlation between hydroid mitochondrial genotype and

308 Sargassum species. We also found significant population genetic structure in A. latecarinata

309 between North Atlantic regions, which was likely due to the distribution of the Sargassum

310 substrates. These findings are consistent with the hypothesis that substrate availability associated

311 with Sargassum species source regions is driving A. latecarinata colonization patterns. However,

312 the detection of two S. fluitans III-derived A. latecarinata colonies in haplotype 1, which was the

313 most common haplotype for S. natans VIII-derived colonies, points to the potential for limited

314 genetic exchange to take place when the Sargassum forms co-occur. We found that $S$. fluitans

315 III and S. natans VIII were sometimes found together at the same sampling site in a given

316 year, as was the case for one of the S. fluitans III-derived A. latecarinata colonies with

317 haplotype 1. While we did not simultaneously collect S. natans VIII for the other S. fluitans 
318 III-derived A. latecarinata colony with haplotype 1, it is possible that it had encountered $S$.

319 natans VIII previously as it drifted through other regions. As such, the dominant population

320 genetic pattern observed in A. latecarinata is likely maintained through settlement on

321 substrates that differ in geographic origins.

322 Aglaophenia species typically lack a planktonic medusa stage (Svoboda \& Cornelius,

323 1991) and have been hypothesized to have limited dispersal capabilities, which could lead to

324 population genetic structuring and speciation (Postaire et al., 2015). However, benthic or fixed

325 stages can also disperse via rafting on algal or other substrates (Ronowicz et al., 2015; Boissin et

326 al., 2018). In contrast to the pattern observed in A. latecarinata, the Sargassum shrimp Latreutes

327 fucorum, which has a long-lived planktonic larval period, exhibited no population genetic

328 structure over the same region (Sehein et al., 2013). This finding could reflect the greater

329 potential of L. fucorum to disperse independently of Sargassum, and reinforces our hypothesis

330 that substrate availability is an important driver of A. latecarinata settlement patterns.

331 Several studies that utilize $16 \mathrm{~S}$ sequences suggest cryptic species are common in

332 aglaopheniid taxa. Schuchert (2014) found that in the aglaopheniid genus Plumularia, nominal

333 morphologically-defined species showed a high degree of genetic variability indicating possible

334 cryptic speciation. Postaire et al. (2016), employing multiple species delimitation methods, found

335 significant variation in mitochondrial 16S sequences within aglaopheniid morphospecies, which

336 also likely indicates cryptic species. In another study of the family, Moura et al. (2012) found

337 that their 16S A. latecarinata sequence from Brazil fell outside of the Aglaophenia clade. Our

338 family-level genetic analysis suggests that the different pelagic Sargassum-associated hydroid

339 genotypes represent intraspecific variation and not cryptic species. Furthermore, our results show

340 that these Sargassum-associated specimens are also likely the same species as those collected 
341 from Central America and Florida in Moura et al. (2018) and from São Sebastião in Brazil

342 (Leclère et al., 2007). However, the sequence from Alagaos, Brazil (Maronna et al., 2006) fell

343 well outside the A. latecarinata clade and so may represent a cryptic species or a

344 misidentification. At a deeper level, our phylogeny indicated that the genus Aglaophenia is

345 polyphyletic, as in previous studies (Moura et al., 2018). Taxonomic studies, coupled with

346 molecular analyses utilizing multiple genetic markers, will be necessary to fully understand

347 aglaopheniid diversity and evolutionary relationships.

\section{Conclusions}

349 A. latecarinata hydroids were abundant on S. natans VIII and S. fluitans III, but rare on S. natans

350 I. For the hydroids on S. natans VIII and S. fluitans III, hydroid mitochondrial genotype was

351 strongly correlated with Sargassum substrate form. There was significant population genetic

352 structure in the hydroids, which likely reflects the distribution of their different algal substrates,

353 with $S$. natans VIII likely annually sourced primarily from the equatorial Atlantic and S. fluitans

354 III likely annually sourced primarily from the Gulf of Mexico. As cryptic speciation appears to

355 be common in aglaopheniids, we conducted a family-level phylogenetic analysis that showed

356 that the genus Aglaophenia was polyphyletic, and that all A. latecarinata haplotypes associated

357 with pelagic Sargassum belonged to the same clade as published sequences from Florida, Central

358 America, and one location in Brazil (São Sebastião). A nominal A. latecarinata sequence from a

359 second Brazilian location (Alagoas) likely belongs to a different species.

\section{Acknowledgments}

362 We thank students and crew of SEA Semester (Sea Education Association, Woods Hole, MA,

363 USA) cruises C259, C263, C266, C273, C277, and C279 for help with Sargassum collection. 
365

366

367

368

369

370

371

372

373

374

375

376

377

378

379

380

381

382

383

384

\section{References}

Boissin E, Hoareau TB, Postaire B, Gravier-Bonnet N, Bourmaud CA. 2018. Cryptic diversity, low connectivity and suspected human-mediated dispersal among 17 widespread Indo-Pacific hydroid species of the south-western Indian Ocean. Journal of Biogeography 45(9):2104-17.

Brooks MT, Coles VJ, Hood RR, Gower JF. 2018. Factors controlling the seasonal distribution of pelagic Sargassum. Marine Ecology Progress Series 599:1-8.

Butler JN, Morris BF, Cadwallader J, Stoner AW. 1983. Studies of Sargassum and the Sargassum community. Bermuda Biological Station Special Publications 22:1-307

Calder DR. 1993. Local distribution and biogeography of the hydroids (Cnidaria) of Bermuda. Caribbean Journal of Science 29(1-2):61-74.

Calder DR. 1995. Hydroid assemblages on holopelagic Sargassum from the Sargasso Sea at Bermuda. Bulletin of Marine Science 56(2):537-46.

Calder DR. 1997. Shallow-water hydroids of Bermuda: superfamily Plumularioidea. Royal Ontario Museum.

Clement M, Posada DC, Crandall KA. 2000. TCS: a computer program to estimate gene genealogies. Molecular Ecology 9(10):1657-9.

Coston-Clements L, Settle LR, Hoss DE, Cross FA. Utilization of the Sargassum habitat by marine invertebrates and vertebrates, a review. NOAA Technical Memorandum NMFSSEFSC-296, 32 p. 
385 Cunha AF, Jacobucci GB. 2010. Seasonal variation of epiphytic hydroids (Cnidaria: Hydrozoa)

386 associated to a subtropical Sargassum cymosum (Phaeophyta: Fucales) bed. Zoologia $38727(6)$.

388 Cunningham CW, Buss LW. 1993. Molecular evidence for multiple episodes of paedomorphosis 389 in the family Hydractiniidae. Biochemical Systematics and Ecology 21(1):57-69.

390 Excoffier L, Lischer HEL. 2010. Arlequin suite ver 3.5: A new series of programs to perform 391 population genetics analyses under Linux and Windows. Molecular Ecology Resources $392 \quad 10: 564-567$.

393 Franks JS, Johnson DR, Ko DS. 2016. Pelagic Sargassum in the Tropical North Atlantic. Gulf 394 and Caribbean Research 27 (1): SC6-SC11. Retrieved from http://aquila.usm.edu/gcr/vol27/iss 1/8

396 Gower JFR, King SA. 2011. Distribution of floating Sargassum in the Gulf of Mexico and the Atlantic Ocean mapped using MERIS. International Journal of Remote Sensing 32(7):1917-1929.

399 Gower J, Young E, King S. 2013. Satellite images suggest a new Sargassum source region in 400 2011. Remote Sensing Letters 4(8):764-773.

401 Guiry MD, Guiry GM. 2018. AlgaeBase. World-wide electronic publication, National University 402 of Ireland, Galway. http://www.algaebase.org; searched on 26 July 2018.

403 Huelsenbeck JP, Ronquist F. 2001. MRBAYES: Bayesian inference of phylogenetic trees. Bioinformatics 17(8):754-5.

405 Kato T, Kumanireng AS, Ichinose I, Kitahara Y, Kakinuma Y, Nishihira M, Kato M. 1975. Active components of Sargassum tortile effecting the settlement of swimming larvae of Coryne uchidai. Cellular and Molecular Life Sciences 31(4):433-4. 
408 Langin K. 2018. Seaweed masses assault Caribbean islands. Science 360(6394):1157-1158.

409 Larkin MA, Blackshields G, Brown NP, Chenna R, McGettigan PA, McWilliam H, Valentin F,

410 Wallace IM, Wilm A, Lopez R, Thompson JD, Gibson TJ, Higgins DG. 2007. Clustal W

411 and Clustal X version 2.0. Bioinformatics 23:2947-2948.

412 Leclère L, Schuchert P, Manuel M. 2007. Phylogeny of the Plumularioidea (Hydrozoa,

413 Leptothecata): evolution of colonial organisation and life cycle. Zoologica Scripta

$414 \quad 36(4): 371-94$.

415 Leclère L, Schuchert P, Cruaud C, Couloux A, Manuel M. 2009. Molecular phylogenetics of

416 Thecata (Hydrozoa, Cnidaria) reveals long-term maintenance of life history traits despite

417 high frequency of recent character changes. Systematic Biology 58(5):509-26.

418 Maronna MM, Miranda TP, Cantero ÁL, Barbeitos MS, Marques AC. 2016. Towards a

419 phylogenetic classification of Leptothecata (Cnidaria, Hydrozoa). Scientific Reports

$420 \quad 6: 18075$.

421 Moser M, Lee D. 2012. Foraging over Sargassum by western North Atlantic seabirds. The

422 Wilson Journal of Ornithology 124:66-72.

423 Moura CJ, Cunha MR, Porteiro FM, Rogers AD. 2012. A molecular phylogenetic appraisal of 424 the systematics of the Aglaopheniidae (Cnidaria: Hydrozoa, Leptothecata) from the 425 426 north-east Atlantic and west Mediterranean. Zoological Journal of the Linnean Society

Moura CJ, Lessios H, Cortés J, Nizinski MS, Reed J, Santos RS, Collins AG. 2018. Hundreds of 428 genetic barcodes of the species-rich hydroid superfamily Plumularioidea (Cnidaria, Medusozoa) provide a guide toward more reliable taxonomy. Scientific reports $8(1): 17986$. 
431 Niermann U. 1986. Distribution of Sargassum natans and some of its epibionts in the Sargasso

432 Sea. Helgoländer Meeresuntersuchungen 40(4):343.

433 Nisihira M. 1965. The association between Hydrozoa and their attachment substrata with special reference to algal substrata. Bulletin of the Marine Biological Station of Asamushi 12(2-

435 3):75-89.

436

(Hydrozoa). Bulletin of the Marine Biological Station of Asamushi 13(2):83-89.

Nisihira M. 1968b. Brief experiments on the effects of algal extracts in promoting the settlement of the larvae of Coryne uchidai Stechow (Hydrozoa). Bulletin of the Marine Biological Station of Asamushi 13(2):91-101.

Nishihira M. 1971. Colonization pattern of hydrozoa on several species of Sargassum. Bulletin of the Marine Biological Station of Asamushi 14(2):99-108.

Oliveira O, Marques A. 2007. Epiphytic hydroids (Hydrozoa: Anthoathecata and Leptothecata) of the world. Check List 3:21.

Parr A. 1939. Quantitative Observations on the Pelagic Sargassum Vegetation of the Western North Atlantic. Bulletin of the Bingham Oceanographic Collection, vol. VI, part 7. Peabody Museum of Natural History, Yale University, New Haven, CT, 93 pp.

Pati AC, Belmonte G. 2018. Asexually generated propagules from subtidal sessile benthic organisms. Progress in Aqua Farming and Marine Biology 1(1):180002.

Posada D, Crandall KA. 1998. Modeltest: testing the model of DNA substitution. Bioinformatics 14(9):817-8.

Postaire B, Magalon H, Bourmaud CA, Bruggemann JH. 2016. Molecular species delimitation methods and population genetics data reveal extensive lineage diversity and cryptic 
species in Aglaopheniidae (Hydrozoa). Molecular phylogenetics and evolution 105:3649.

456

457

458

Putman NF, Goni GJ, Gramer LJ, Hu C, Johns EM, Trinanes J, Wang M. 2018. Simulating transport pathways of pelagic Sargassum from the Equatorial Atlantic into the Caribbean Sea. Progress in Oceanography 165: 205-214. doi:10.1016/j.pocean.2018.06.009

QGIS Development Team. 2018. QGIS Geographic Information System. Open Source Geospatial Foundation Project. http://qgis.osgeo.org.

Ronowicz M, Kukliński P, Mapstone GM. 2015. Trends in the diversity, distribution and life history strategy of Arctic Hydrozoa (Cnidaria). PloS one 10(3):e0120204.

Ryland JS. 1974. Observations on some epibionts of gulf-weed, Sargassum natans (L.) Meyen. Journal of Experimental Marine Biology and Ecology 14(1):17-25.

Schell JM, Goodwin DS, Siuda ANS. 2015. Recent Sargassum inundation events in the Caribbean: Shipboard observations reveal dominance of a previously rare form. Oceanography 28(3):8-10, http://dx.doi.org/10.5670/oceanog.2015.70.

Schlitzer R. 2018. Ocean Data View. odv.awi.de.

Schuchert P. 2014. High genetic diversity in the hydroid Plumularia setacea: a multitude of cryptic species or extensive population subdivision? Molecular Phylogenetics and Evolution 76:1-9.

Sehein T, Siuda AN, Shank TM, Govindarajan AF. 2014. Connectivity in the slender Sargassum shrimp (Latreutes fucorum): implications for a Sargasso Sea protected area. Journal of Plankton Research 36(6):1408-12.

Stoner AW. 1983. Pelagic Sargassum: evidence for a major decrease in biomass. Deep Sea Research Part A. Oceanographic Research Papers 30(4):469-74. 
477 Svoboda A, Cornelius PF. 1991. The European and Mediterranean species of Aglaophenia 478 (Cnidaria: Hydrozoa). Zoologische Verhandelingen 274:

479 Swofford DL. 2003. PAUP*. Phylogenetic Analysis Using Parsimony (*and Other Methods).

$480 \quad$ Version 4. Sinauer Associates, Sunderland, Massachusetts.

481 Ullman DS, Cornillon PC, Shan Z. 2007. On the characteristics of subtropical fronts in the North $482 \quad$ Atlantic. Journal of Geophysical Research (Oceans) 112: C01010.

483 Wang M, Hu C. 2017. Predicting Sargassum blooms in the Caribbean Sea from MODIS 484 observations. Geophysical Research Letters 44:3265-3273.

485 Wang M, Hu C, Barnes BB, Mitchum G, Lapointe B, Montoya JP. 2019. The great Atlantic $486 \quad$ Sargassum belt. Science 365:83-87.

487 Weis JS. 1968. Fauna associated with pelagic Sargassum in the Gulf Stream. American Midland $488 \quad$ Naturalist 80(2):554-8.

489 Wells R, Rooker J. 2004. Spatial and temporal habitat use by fishes associated with Sargassum 490 mats in the NW Gulf of Mexico. Bulletin of Marine Science 74:81-89.

491 Witherington B, Hirama S, Hardy R. 2012. Young sea turtles of the pelagic Sargassum-

492 dominated drift community: habitat use, population density, and threats. Marine Ecology 493 Progress Series 463:1-22. 


\section{Figure 1}

Morphological differences between Sargassum forms as described in Parr (1939) and Schell et al. (2015).

S. fluitans have thorny stems whereas $S$. natans have smooth stems. Bladder and blade attributes differ widely among forms. A) For S. fluitans III, thorns on stem are present, blades are wide, bladders are devoid of spines, and bladders are oblong. B) For S. natans I, stem is smooth, blades are narrow, spines are present on bladders, and bladders are spherical C) For

S. natans VIII (photo credit: Janet Bering), stem is smooth, blades are wide, bladders are devoid of spines, and bladders are spherical.
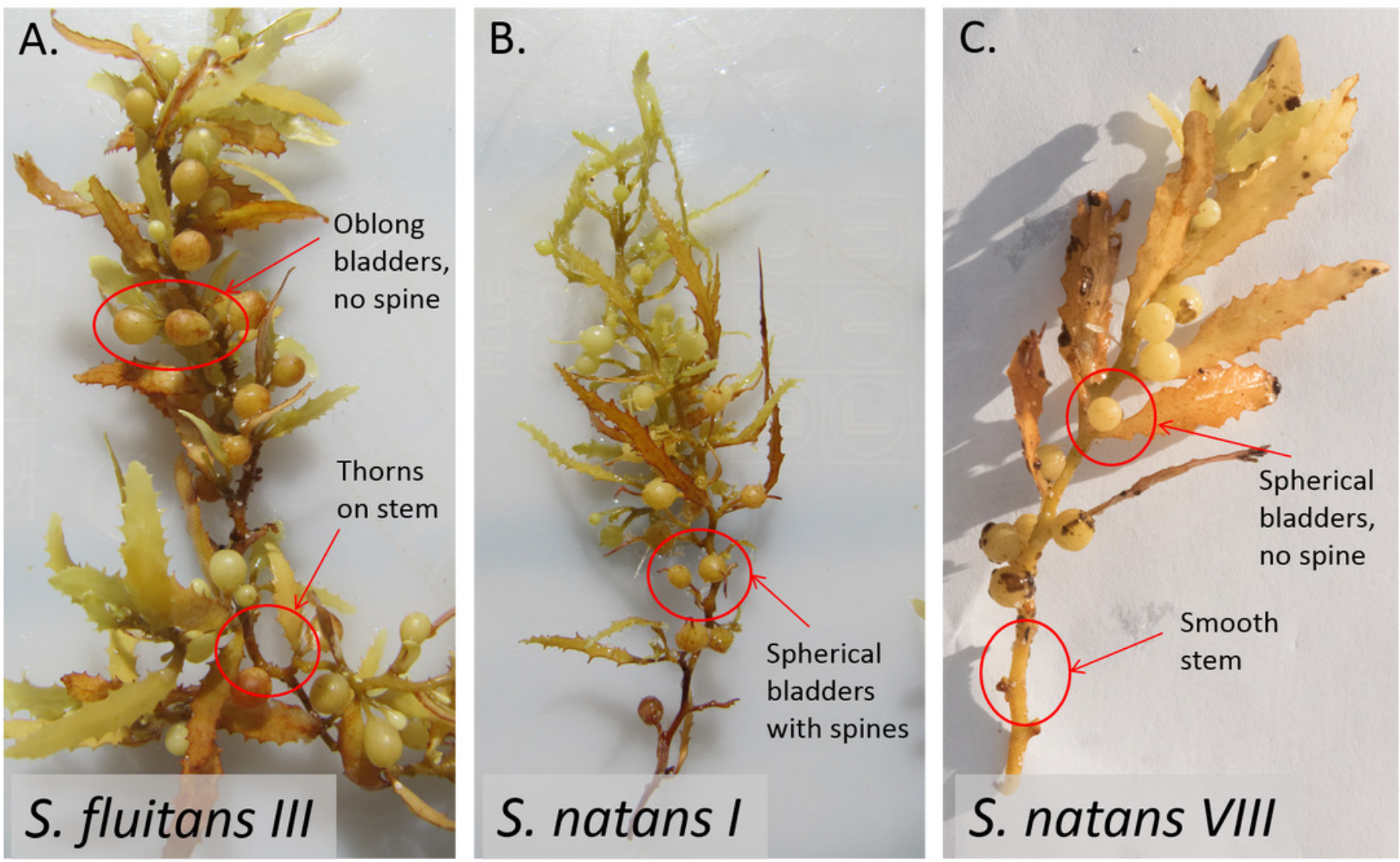


\section{Figure 2}

Aglaophenia latecarinata hydroids.

A) Isolated Aglaophenia latecarinata specimen. B) A colony of the epiphytic hydroid species, Aglaophenia latecarinata, attached to Sargassum stem. Arrow points to stolon connecting genetically identical units of a single colony.
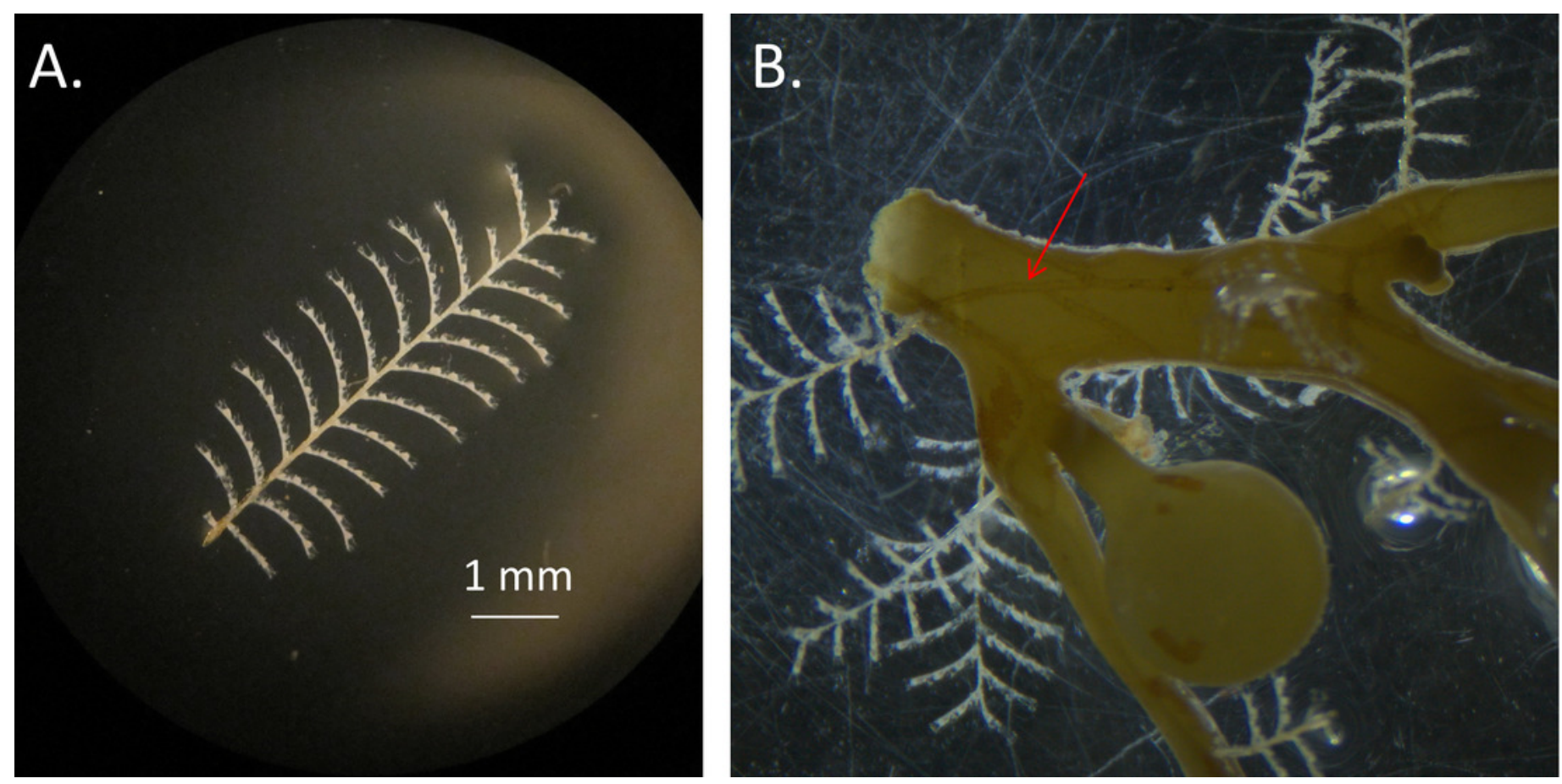


\section{Figure 3}

Cruise tracks.

Each cruise is represented by a different color. Cruise labels are Sea Education Association cruise numbers. C259 and C263 took place in 2015, C266 took place in 2016, C273 took place in 2017, and C277 and C279 took place in 2018.

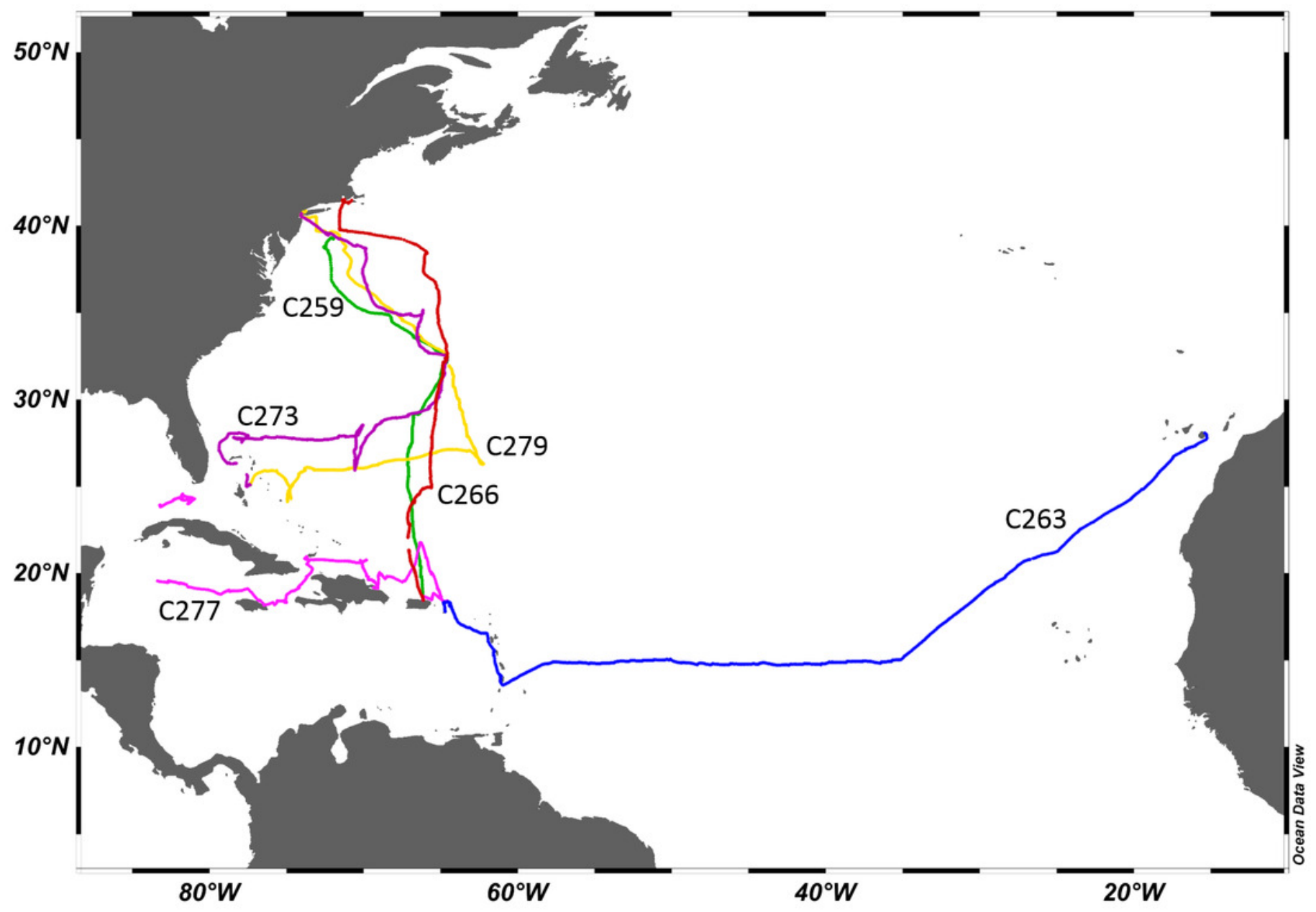


Figure 4

Figure 4. Geographic distribution of hydroid samples by Sargassum form.

Lines indicate boundaries between oceanographic regions (Gulf Stream, North Sargasso Sea, South Sargasso Sea, Tropical Atlantic, and Caribbean) as described in the text. Each circle represents a single station and circle size corresponds to the number of Sargassum samples collected at each station. Yellow indicates stations where only S. fluitans III was collected, green indicates stations where only S. natans VIII was collected, and maroon indicates stations where both S. fluitans III and S. natans VIII were collected.

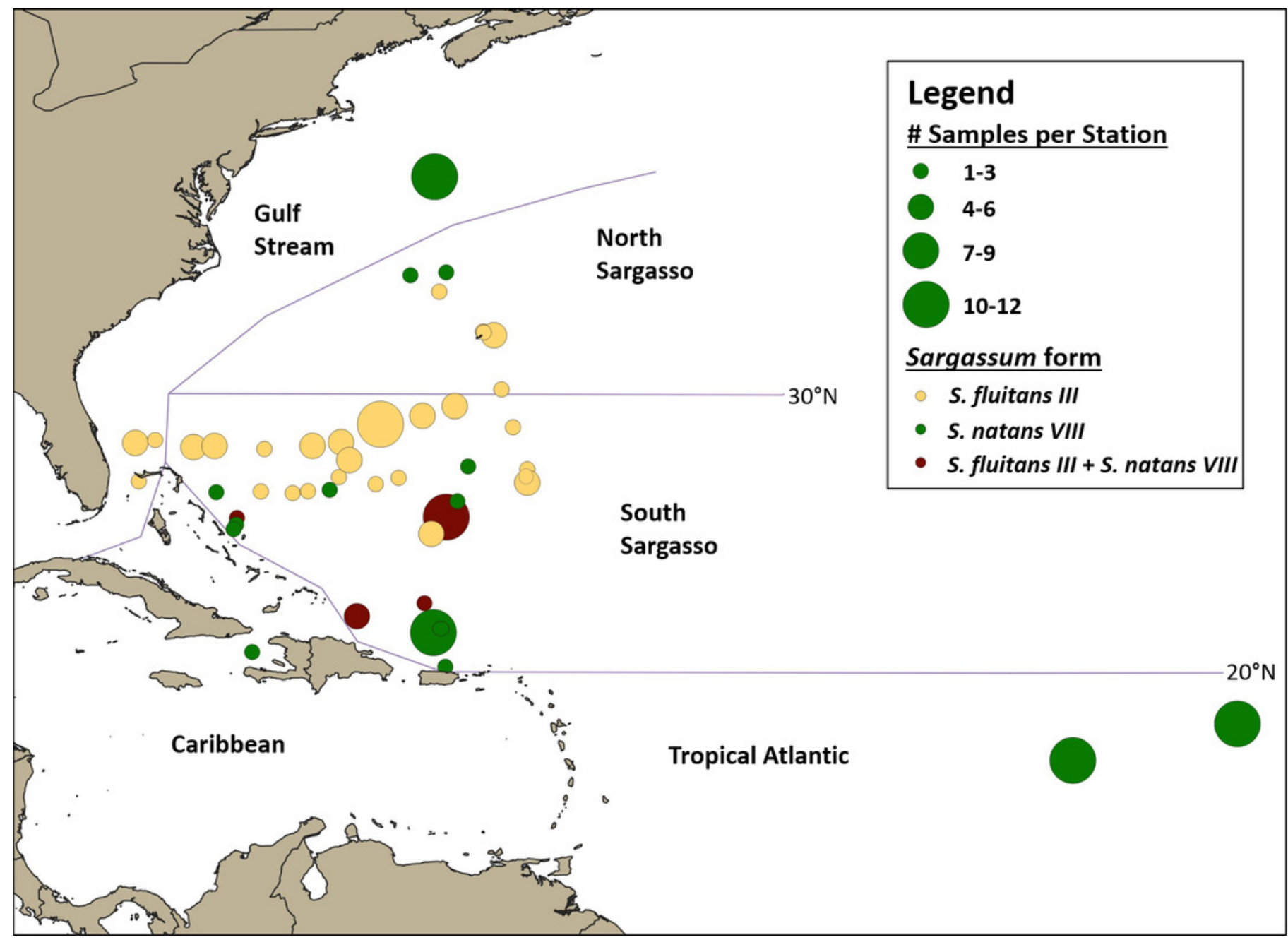




\section{Figure 5}

Haplotype network of Aglaophenia latecarinata sequences.

Circle size reflects the number of individuals possessing a given haplotype (n). Yellow indicates hydroids found on S. fluitans III and green indicates hydroids found on S. natans VIII.

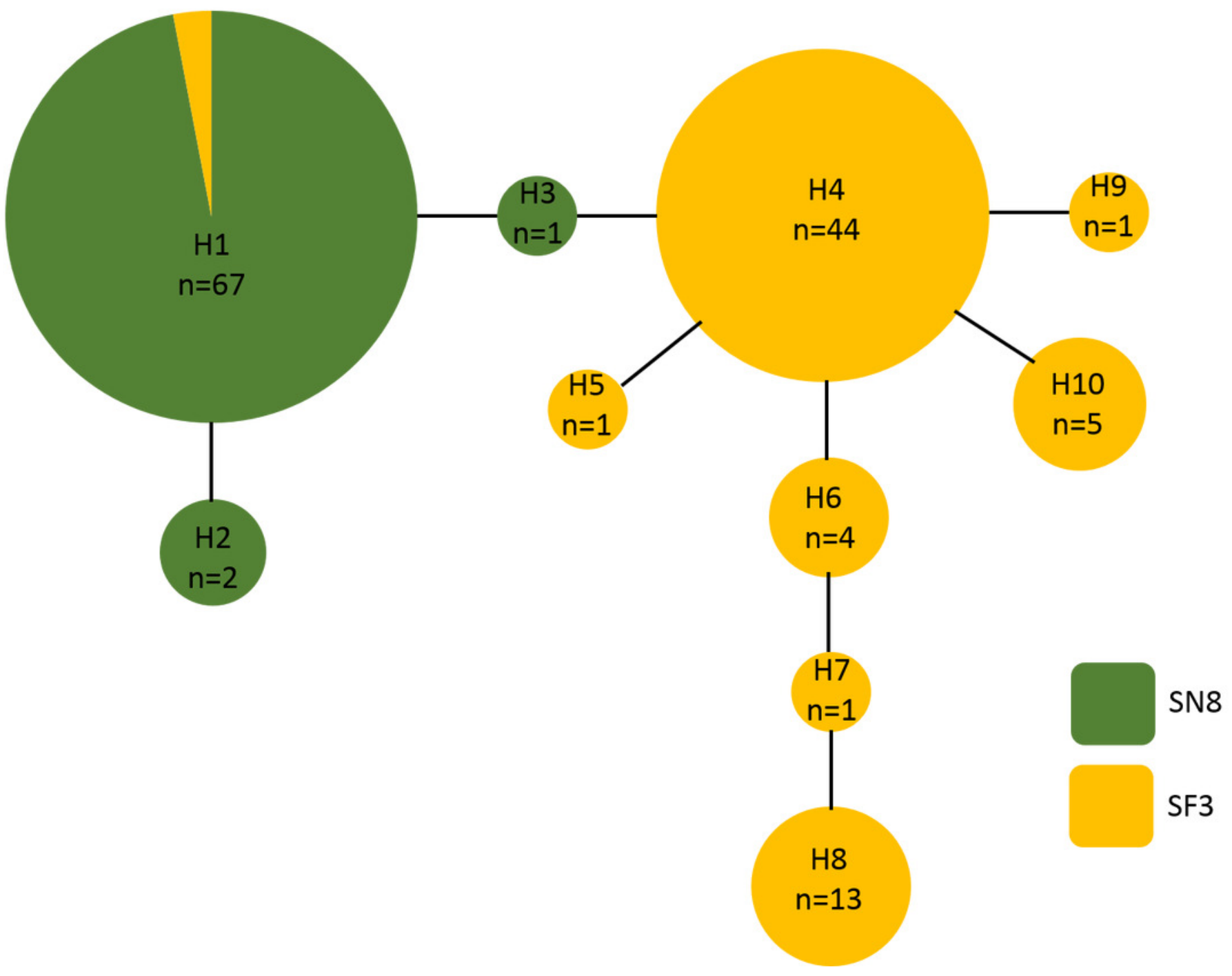


Figure 6

Maximum likelihood phylogeny of the Aglaopheniidae.

Support for nodes is indicated by ML bootstrap values before the slash (only those above 50 are shown) and Bayesian posterior probabilities after the slash (only those above .5 are shown). A. latecarinata sequences are highlighted in red.

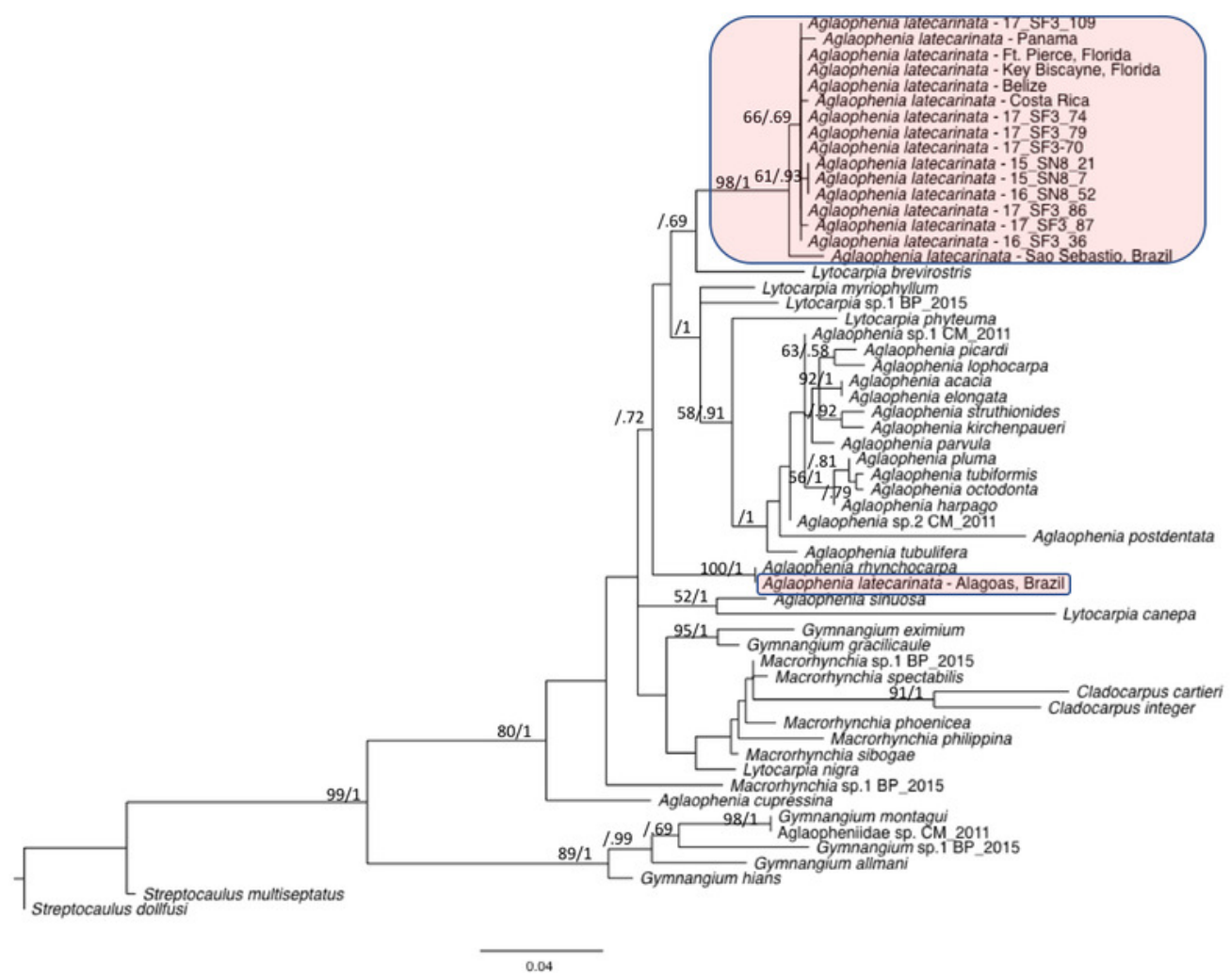




\section{Table $\mathbf{1}$ (on next page)}

Sample summary.

Number of hydroids samples collected from each Sargassum substrate by geographic region. 
1

\begin{tabular}{|l|c|c|c|c|c|c|c|c|c|c|}
\hline & \multicolumn{2}{|c|}{2015} & \multicolumn{2}{c|}{2016} & \multicolumn{2}{c|}{2017} & \multicolumn{2}{c|}{ To18 } \\
\cline { 2 - 12 } & Sn8 & Sf3 & Sn8 & Sf3 & Sn8 & Sf3 & Sn8 & Sf3 & Sn8 & Sf3 \\
\hline S. Sargasso & 1 & 0 & 20 & 8 & 0 & 36 & 11 & 14 & 32 & 58 \\
\hline N. Sargasso & 0 & 0 & 0 & 0 & 3 & 2 & 0 & 6 & 3 & 8 \\
\hline Tropical Atl. & 20 & 0 & 0 & 0 & 0 & 0 & 0 & 0 & 20 & 0 \\
\hline Gulf Stream & 0 & 0 & 12 & 0 & 0 & 5 & 0 & 0 & 12 & 5 \\
\hline Caribbean & 0 & 0 & 0 & 0 & 0 & 0 & 1 & 0 & 1 & 0 \\
\hline Total & 21 & 0 & 32 & 8 & 3 & 43 & 12 & 20 & $\mathbf{6 8}$ & $\mathbf{7 1}$ \\
\hline
\end{tabular}

2 
Table 2 (on next page)

Analysis of Molecular Variance (AMOVA) results. 


\begin{tabular}{|l|l|l|l|l|}
\hline Source of & d.f. & Sum of squares & Variance & Percentage of \\
variation & 3 & 6.171 & $0.07200 \mathrm{Va}$ & 19.77 \\
\hline Amopulations & & & & \\
\hline Within & & & $0.29210 \mathrm{Vb}$ & 80.23 \\
\hline populations & 135 & 39.433 & & \\
\hline Total & 138 & 45.604 & 0.36410 & \\
\hline Fixation index & 0.19774 & & & \\
\hline
\end{tabular}




\section{Table 3(on next page)}

Population pairwise $\mathrm{F}_{\mathrm{ST}}$ 's (below the diagonal) and p-values (above the diagonal).

TA = Tropical Atlantic; SS = South Sargasso Sea; NS = North Sargasso Sea; GS = Gulf Stream. 
1

\begin{tabular}{|l|l|l|l|l|}
\hline & TA & SS & NS & GS \\
\hline TA & - & $0.00000+-0.0000$ & $0.00000+-0.0000$ & $0.01802+-0.0182$ \\
\hline SS & 0.29003 & - & $0.22523+-0.0389$ & $0.00901+-0.0091$ \\
\hline NS & 0.62631 & 0.02030 & - & $0.00901+-0.0091$ \\
\hline GS & 0.12084 & 0.10557 & 0.24759 & - \\
\hline
\end{tabular}

2

3 


\section{Table 4(on next page)}

Aglaopheniid sequences from GenBank used in the phylogenetic analysis.

Sampling locations are given for $A$. latecarinata sequences. 


\begin{tabular}{|c|c|c|c|c|}
\hline Genus & Species & Reference & $\begin{array}{l}\text { Genbank } \\
\text { accession \# }\end{array}$ & $\begin{array}{l}\text { Location } \\
\text { (A. latecarinata) }\end{array}$ \\
\hline \multirow[t]{11}{*}{ Aglaophenia } & \multirow[t]{7}{*}{ latecarinata } & Moura et al., 2018 & MH212420 & Carrie Bow Key, Belize \\
\hline & & Moura et al., 2018 & MH212421 & $\begin{array}{l}\text { Ft. Pierce, FL, USA } \\
\text { (on Sargassum) }\end{array}$ \\
\hline & & Moura et al., 2018 & MH212422 & Isla Tambor, Panama \\
\hline & & Moura et al., 2018 & MH212423 & Isla Uvita, Costa Rica \\
\hline & & Moura et al., 2018 & MH212424 & $\begin{array}{l}\text { Key Biscayne, FL, } \\
\text { USA }\end{array}$ \\
\hline & & Maronna et al., 2016 & KT266600 & $\begin{array}{l}\text { Barra do São Miguel, } \\
\text { Alagoas, Brazil }\end{array}$ \\
\hline & & Leclère et al., 2007 & DQ855936 & $\begin{array}{l}\text { Ponta do Baleeiro, São } \\
\text { Sebastião, Brazil }\end{array}$ \\
\hline & acacia & Leclère et al., 2009 & FJ550507 & \\
\hline & cupressina & Postaire et al., 2016 & KM587399 & \\
\hline & elongata & Leclère et al., 2009 & FJ550508 & \\
\hline & harpago & Moura et al., 2012 & JN560129 & \\
\hline
\end{tabular}




\begin{tabular}{|c|c|c|c|c|}
\hline & kirchenpaueri & Moura et al., 2012 & JN560124 & \\
\hline & lophocarpa & Moura et al., 2012 & JN560112 & \\
\hline & octodonta & Leclaire et al., 2017 & DQ855915 & \\
\hline & parvula & Moura et al., 2012 & JN560097 & \\
\hline & picardi & Moura et al., 2012 & JN560105 & \\
\hline & pluma & Moura et al., 2012 & JN560130 & \\
\hline & postdentata & Postaire et al., 2016 & KM587408 & \\
\hline & rhynchocarpa & Maronna et al., 2016 & KT266601 & \\
\hline & sinuousa & Postaire et al., 2016 & KM587411 & \\
\hline & struthionides & Maronna et al., 2016 & KT266602 & \\
\hline & tubiformis & Leclaire et al., 2017 & DQ855917 & \\
\hline & tubulifera & Moura et al., 2012 & JN560117 & \\
\hline & sp. 1 (CM 2011) & Moura et al., 2012 & JN560094 & \\
\hline & sp. 2 (CM 2011) & Moura et al., 2012 & JN560101 & \\
\hline Cladocarpus & cartieri & Moura et al., 2012 & JN560085 & \\
\hline & integer & Leclaire et al., 2012 & FJ550512 & \\
\hline
\end{tabular}




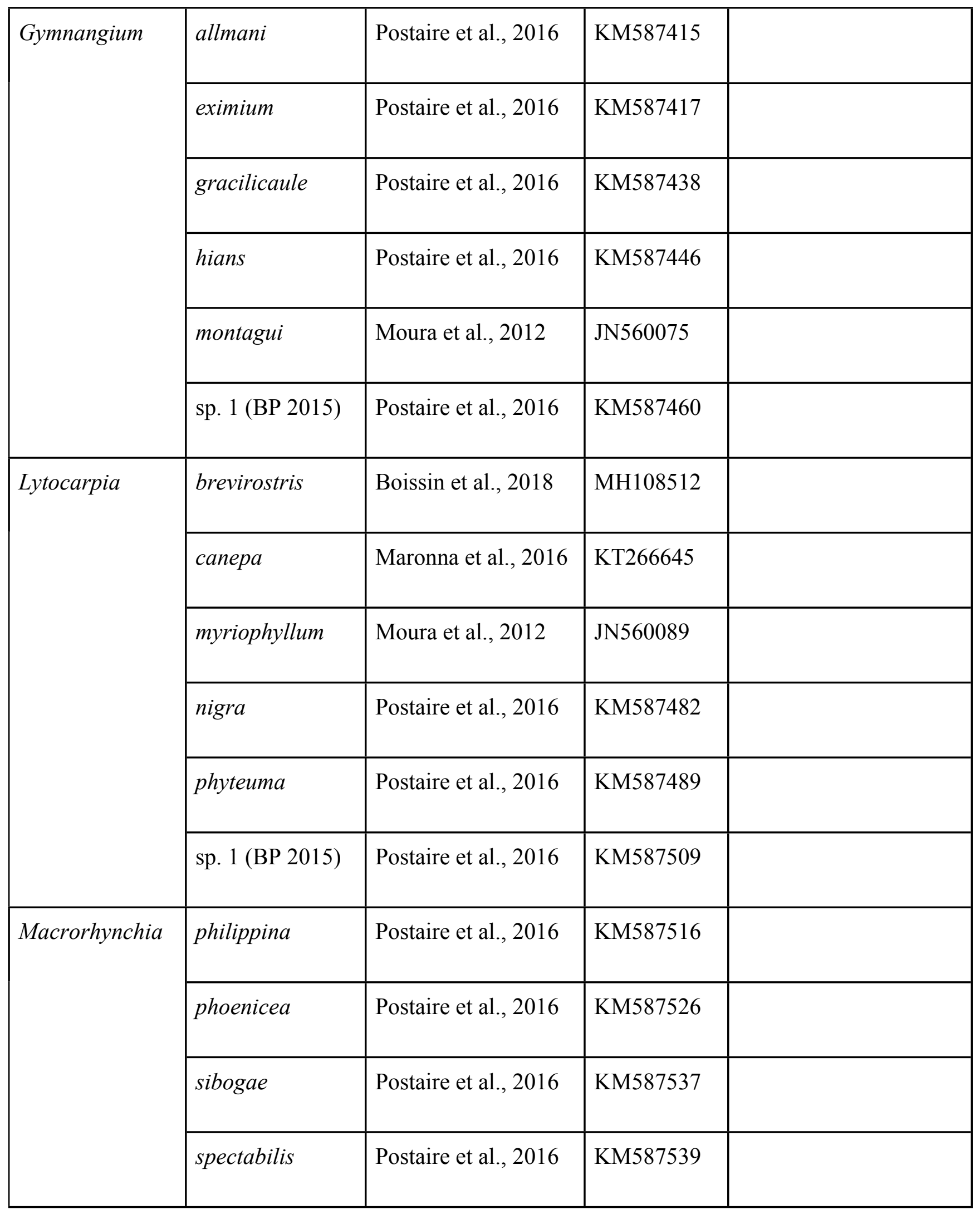




\begin{tabular}{|l|l|l|l|l|}
\hline & sp. 1 (BP 2015) & Postaire et al., 2016 & KM587538 & \\
\cline { 2 - 5 } & sp. 2 (BP 2015) & Postaire et al., 2016 & KM587510 & \\
\hline Streptocaulus & multiseptatus & Moura et al., 2012 & JN560080 & \\
\cline { 2 - 5 } & dollfusi & Moura et al., 2012 & JN560081 & \\
\hline Aglaopheniidae & sp. (CM 2011) & Moura et al., 2012 & JN560079 & \\
& & & & \\
\hline
\end{tabular}

2 